\title{
Desidratação osmótica de peras: compostos bioativos e avaliação sensorial
}

\section{Osmotic dehydration of pears: bioactive compounds and sensory evaluation}

Deshidratación osmótica de peras: compuestos bioactivos y evaluación sensorial

\author{
Izabella Renatta Almeida de Carvalho ${ }^{1}$ \\ Lilliam May Grespan Estodutto da Silva ${ }^{2}$ \\ Raquel Pires Campos ${ }^{3}$ \\ Juliana Rodrigues Donadon ${ }^{4}$
}

${ }^{1}$ Farmacêutica pela Universidade Federal de Mato Grosso do Sul. E-mail: izabella.renatta@gmail.com, Orcid: https://orcid.org/0000-0002-6191-2754

${ }^{2}$ Doutora em Ciências da Saúde pela Universidade Federal de Mato Grosso do Sul. Professora na Universidade Católica Dom Bosco, Campo Grande, MS. E-mail: Imaygrespan@gmail.com, Orcid: https://orcid.org/0000-0001-72642617

${ }^{3}$ Doutora em Produção Vegetal pela Universidade Estadual de Maringá. Professora Adjunta na Universidade Federal de Mato Grosso do Sul, Campo Grande, MS. E-mail: raquel.campos@ufms.br, Orcid: https://orcid.org/0000-0001-7081-7735

${ }^{4}$ Doutora em Agronomia, Produção Vegetal, pela Universidade Estadual Paulista, Profa Adjunto da Universidade Federal de Mato Grosso do Sul, Campo Grande, MS.E-mail: juliana.donadon@ufms.br, Orcid: http://orcid.org/0000-0003-3657-2206 
Resumo: Objetivou-se, neste trabalho, a avaliação físico-química e sensorial de peras cv. Williams submetidas à desidratação osmótica seguida por secagem convencional. Os frutos foram adquiridos na Ceasa de Campo Grande, MS, sanitizados e cortados em pedaços, posteriormente divididos em quatro tratamentos, variando-se a concentração de sólidos solúveis do xarope de imersão para desidratação osmótica (Controle ou $0^{\circ}$ Brix; $40^{\circ}$ Brix; $55^{\circ}$ Brix; $70^{\circ}$ Brix). Após imersão, os pedaços foram desidratados em secador convencional de leito fixo a $60^{\circ} \mathrm{C}$, até alcançar, aproximadamente, $20 \%$ (bu) de umidade. As peras desidratadas foram avaliadas quanto à composição centesimal, $\mathrm{pH}$ e quanto aos teores de fenóis totais, taninos, atividade antioxidante e análise sensorial. Analisando os valores de bioativos em $20 \%$ (bu) de umidade, verificou-se que os teores de fenóis totais e taninos aumentaram ao incrementar sólidos nos pedaços. Os produtos desidratados a $40^{\circ}$ Brix apresentaram maior capacidade em sequestrar radicais livres. Os pedaços desidratados a $70^{\circ}$ Brix foram os preferidos por provadores

Palavras-chave: Pyrus communins L.; secagem; solução osmótica; atividade antioxidante

\begin{abstract}
The objective of this work was to evaluate physic-chemically and sensorially pears submitted to osmotic dehydration followed by conventional drying. The fruits were purchased at the Ceasa of Campo Grande, MS, sanitized and cut into pieces, later on, separated into four different treatments, varying the soluble solids concentration of the immersion syrup for osmotic dehydration (Control or $0^{\circ}$ Brix; $40^{\circ}$ Brix; $55^{\circ}$ Brix; $70^{\circ}$ Brix). After immersion, the pieces were dehydrated in a conventional fixed tray dryer at $60^{\circ} \mathrm{C}$ until approximately $20 \%$ (bu) of moisture was reached. The dehydrated pears were evaluated for centesimal composition, $\mathrm{pH}$, and total phenol contents, tannins, antioxidant activity, and sensory analysis. Analyzing the bioactive values in $20 \%$ (bu) of humidity, it was verified that the total phenols and tannins contents increased by incrementing solids to the pieces. The products dehydrated at $40^{\circ}$ Brix presented greater capacity to steal free radicals. The pieces dehydrated at $70^{\circ}$ Brix were preferred by tasters.
\end{abstract}

Keywords: Pyrus communins L.; drying; osmotic solution; bioactive compounds.

Resumen: El objetivo de este trabajo fue evaluar físico-químicamente y sensorialmente peras sometidas a deshidratación osmótica seguida por un secado convencional. Los frutos fueron adquiridos en la Ceasa de Campo Grande, MS, desinfectados y cortados en trozos, posteriormente fueron divididos en cuatro tratamientos, variando la concentración de sólidos solubles del jarabe de inmersión, para deshidratación osmótica (Control o $0^{\circ}$ Brix; $40^{\circ}$ Brix; $55^{\circ}$ Brix, $70^{\circ}$ Brix). Después de la inmersión, los pedazos fueron deshidratados en un secador convencional de lecho fijo a $60^{\circ} \mathrm{C}$, hasta alcanzar aproximadamente el $20 \%$ (bu) de humedad. Las peras deshidratadas fueron evaluadas en cuanto a la composición centesimal, pH y en cuanto a los contenidos de fenoles totales, taninos, actividad antioxidante y análisis sensorial. Al analizar los valores de bioactivos en un 20\% (bu) de humedad, se verificó que los niveles de fenoles totales y taninos aumentaron al incrementar sólidos en los pedazos. Los productos deshidratados a $40^{\circ}$ Brix presentaron mayor capacidad en secuestrar radicales libres. Los pedazos deshidratados a $70^{\circ}$ Brix fueron los preferidos por los probadores.

Palabras clave: Pyrus communins L.; secado; solución osmótica; compuestos bioactivos. 


\section{CONSIDERAÇÕES INICIAIS}

As peras (Pyrus communins L.) são cultivadas em áreas de clima temperado dos dois hemisférios. Podem também crescer em clima tropical, mas é necessário um processo de cultivo diferenciado; sendo assim, a produção de pera é predominante em regiões temperadas do mundo. A pera é a terceira fruta mais produzida no mundo, depois da uva e da maçã. Pode ser consumida in natura ou destinada ao processamento para obtenção de doces em calda, frutas desidratadas, sucos e vinhos.

O clima e as distâncias entre os grandes centros de produção e de consumo são alguns dos motivos que justificam o uso de tratamentos alternativos para estender a vida de prateleira de alimentos perecíveis, incluindo as frutas, facilitando o transporte para destinos distantes, sem risco de deterioração. A desidratação osmótica é uma técnica que diminui a atividade de água, resultando em alimentos com características adequadas para o armazenamento e com composição química próxima aos in natura; no entanto, pode melhorar a cor, o sabor e o aroma.

A desidratação osmótica é uma operação preliminar que consiste na imersão do alimento sólido, inteiro ou em pedaços, em solução aquosa concentrada de açúcares, resultando em dois fluxos de massas simultâneos: fluxo de água do alimento para a solução, devido à diferença na pressão osmótica; e de soluto da solução para o alimento, devido à diferença nos gradientes de concentração. A desidratação osmótica é uma tecnologia importante para o desenvolvimento de produtos derivados de frutas com valor agregado, a qual possivelmente pode preservar as propriedades bioativas e funcionais.

Em abacaxis das cultivares Pérola e Smooth Cayenne fatiados, Dionello et al. (2009) detectaram perda de água e ganho de sólidos após desidratação osmótica em xarope de açúcar invertivo, por duas horas, adotando a relação fruta:xarope de $1: 10$, nas temperaturas de $40^{\circ} \mathrm{C}$ e $50^{\circ} \mathrm{C}$, sendo a perda de água maior em fatias desidratadas sem agitação para cultivar Smooth Cayenne desidratada com xarope a $50^{\circ} \mathrm{C}$.

A cinética de desidratação osmótica em pedaços de pera em soluções osmóticas de $45^{\circ}$ e $65^{\circ}$ Brix foi estudada por Takahashi e Ravelli (2005), no entanto não há estudos sobre a aceitação sensorial de peras desidratadas 
em diferentes concentrações de soluções osmóticas, bem como sobre a retenção de compostos bioativos após desidratação.

A secagem convencional, em secador de leito fixo, com ar forçado, utilizada na obtenção de frutas desidratadas, visa à remoção parcial da água contida nos alimentos até o teor recomendado para armazenamento seguro. Nesta operação, as condições do ar de secagem devem ser monitoradas para minimizar alterações indesejáveis na cor, no aroma e na textura. Tratamentos adicionais são utilizados previamente à secagem convencional, com o objetivo de minimizar alterações na cor provenientes do escurecimento enzimático, durante a preparação e secagem. O ácido cítrico é um aditivo com ação antioxidante permitido pela legislação para inibir o escurecimento enzimático de frutas desidratadas.

O desenvolvimento de produtos de fácil consumo e que apresentem qualidade sensorial e nutricional é necessário para atender os consumidores, cada vez mais seletivos e exigentes na hora de optar pelos produtos oferecidos, pois estão preocupados com estilo e qualidade de vida mais saudável. Dessa forma, o presente trabalho tem por objetivo avaliar físico-quimicamente e sensorialmente peras submetidas à desidratação em diferentes concentrações de solução osmótica seguida por secagem convencional.

\section{MATERIAL E MÉTODOS}

Os frutos de peras cultivar Williams foram adquiridos na Ceasa de Campo Grande, MS, transportados ao Laboratório de Processamento de Alimentos da Unidade de Tecnologia em Alimentos (Unital) da Universidade Federal de Mato do Sul (UFMS), selecionados de acordo com seus atributos de qualidade, descartando-se os injuriados, deformados, verdes, doentes e em senescência. Os frutos maduros e sadios foram lavados em água corrente e sanitizados por imersão em solução com 200 mg L-1 de cloro ativo, por 10 minutos.

O estágio de maturação dos frutos foi caracterizado por meio das seguintes avaliações: textura, determinada utilizando-se penetrômetro da marca Instrutherm, modelo PTR-300 e ponteira de 8 mm; acidez titulável 
(AT) e sólidos solúveis (SS), de acordo com as metodologias do Instituto Adolfo Lutz (IAL) (2008). O ratio foi obtido pela relação entre os teores de SS e AT (SS/AT).

Os frutos sanitizados, massa total de $20 \mathrm{~kg}$, foram enxaguados em água corrente e cortados longitudinalmente, e as metades foram divididas novamente em três pedaços, com aproximadamente $3 \mathrm{~cm}$ de espessura. A uniformidade no corte foi determinante para obter um produto padronizado. Os pedaços foram imersos em solução de ácido cítrico a 1\%, por 10 minutos, divididos em quatro lotes de $4,5 \mathrm{~kg}$ e submetidos ao tratamento osmótico por 4 horas (controle $=0^{\circ}$ Brix; $40^{\circ}$ Brix; $55^{\circ}$ Brix e $70^{\circ}$ Brix), visando à redução parcial da atividade de água. Para cada tratamento, os produtos foram elaborados em três repetições, com 1,5 kg em cada uma.

Os xaropes foram preparados por meio da adição de açúcar cristalizado granulado à água (até atingir o teor de sólidos solúveis desejado), sob aquecimento. A quantidade de xarope utilizada no processo foi a necessária para se estabelecer a proporção fruta: xarope de 1:3. Durante a desidratação osmótica, avaliou-se a perda de água, a perda de massa e o incremento de sólidos de acordo com Souza Neto et al. (2005).

Em seguida ao período de desidratação osmótica, os pedaços de cada tratamento foram drenados e colocados em secador de leito fixo, tipo cabine com ar forçado a uma temperatura de $60^{\circ} \mathrm{C}(9,8 \pm 3,11 \%$ de umidade relativa), até atingirem umidade de $20-25 \%$ (bu) e atividade de água entre 0,65-0,75. A perda de água foi acompanhada por gravimetria pesando as amostras em intervalos de aproximadamente $1 \mathrm{~h}$.

Os produtos foram retirados do secador e acondicionados em recipiente protegido com tela, para evitar contaminação por insetos, até atingirem a temperatura ambiente. Em seguida, foram embalados em sacos de polietileno de alta densidade, selados e armazenados à temperatura ambiente $\left(25^{\circ} \mathrm{C}\right)$, para realização dos testes de qualidade. Todas as avaliações foram realizadas em triplicatas.

A composição centesimal dos produtos foi determinada segundo metodologias propostas pelo Instituto Adolfo Lutz (IAL, 2008). O teor de umidade dos produtos foi determinado pelo método gravimétrico em estufa a $105^{\circ} \mathrm{C}$ até peso constante (IAL, 2008). 
O teor de cinzas (\%) foi determinado por meio de incineração da amostra seca, obtida após determinação de umidade, em uma mufla a $550^{\circ} \mathrm{C}$ até coloração branca ou cinza claro, e o de carboidratos, pelo método de glicídios totais, que se baseia na redução dos íons cúpricos do reativo de Fehling a íons cuprosos. A solução da amostra foi com solução de Fehling até que a coloração mudou de azul para incolor. O teor de proteína foi quantificado pelo método de Micro-Kjeldahl, o teor de nitrogênio total da amostra foi convertido em proteína utilizando-se o fator de conversão 5,75, usado para proteínas vegetais. Os resultados foram expressos em \%, em relação à massa da amostra seca. A extração de lipídios foi realizada com hidrólise ácida prévia da amostra, a partir da adição de $100 \mathrm{ml}$ de água quente e $60 \mathrm{ml}$ de $\mathrm{HCl}$ 8M. Após aquecimento e filtragem, o filtrado foi transferido para um funil de separação e recolhida a fase etérea, colocada no balão junto ao extrator de Soxhlet, com o cartucho da amostra filtrada. Os resultados foram expressos em porcentagem.

A fibra alimentar total foi calculada por diferença, conforme equação 1.

Equação 1: Fibras $=100-$ (umidade + cinzas + lipídios + proteínas + carboidratos).

A energia dos produtos foi calculada utilizando-se os fatores de conversão de Atwater: $4 \mathrm{kcal} / \mathrm{g}$ (proteína), $4 \mathrm{kcal} / \mathrm{g}$ (carboidratos) e $9 \mathrm{kcal} / \mathrm{g}$ (lipídios), como mostra a Equação 2.

Equação 2: Energia $=4$ X carboidratos (g) + 9 X lipídios (g) +4 X proteínas (g).

O teor de sólidos solúveis dos produtos (SS) foi determinado segundo metodologia do Instituto Adolfo Lutz (2008), por meio de refratômetro digital. Para determinação do $\mathrm{pH}$, foi utilizado potenciômetro calibrado com tampão de $\mathrm{pH}$ 7,0 e 4,0. Os fenóis totais e a capacidade antioxidante dos produtos dos diferentes tratamentos foram avaliados em extratos aquosos (ROESLER et al. 2007). Os extratos foram submetidos à reação colorimétrica de determinação de compostos fenólicos conforme Swain e Hills (1959). Na determinação da capacidade antioxidante, o valor de IC50 foi definido como a concentração final do extrato integral requerido para decrescer a concentração inicial de DDPH em $50 \%$. Os taninos totais foram determinados por método colorimétrico, baseado na redução de fosfotungstomolibidico (Folin-Dennis), conforme metodologia do Instituto Adolfo Lutz (2008). 
A análise sensorial das peras foi realizada após aprovação do Comitê de Ética em Pesquisa, da Universidade Federal de Mato Grosso do Sul, sob o número do CAAE 89553318.4.0000.0021. Para os testes de aceitação dos produtos, utilizou-se escala hedônica estruturada de 7 pontos, em que $1=$ desgostei muito; 2 = desgostei moderadamente; 3 = desgostei ligeiramente; 4 = nem gostei, nem desgostei; 5 = gostei ligeiramente; 6 = gostei moderadamente e 7 = gostei muito. Os atributos avaliados foram: aspecto global, sabor e consistência. A intenção de compra foi avaliada por meio de escala estruturada de cinco pontos, em que 1 = certamente não compraria; 2 = possivelmente não compraria; 3 = talvez compraria/talvez não compraria; 4 = possivelmente compraria e 5 = certamente compraria (IAL, 2008).

Os resultados das avaliações foram submetidos à análise de variância e as médias foram comparadas pelo teste de Tukey ao nível de 5\% de probabilidade.

\section{RESULTADOS E DISCUSSÃO}

As peras in natura apresentaram 13,3 Brix, 0,34 g 100 g-1 de ácido málico, 67,13 N de firmeza e ratio de 38,8. Lombardi et al. (2000) verificaram aumento nos teores de sólidos solúveis de peras, cultivar Shinsseiki, durante a maturação, e redução na firmeza. Depois de 140 dias da floração, encontraram $11,30^{\circ}$ Brix, $60 \mathrm{~N}$ de firmeza e ratio de 37,6, valores próximos aos obtidos neste trabalho. As peras in natura apresentaram $82,72 \%$ de umidade, valor similar ao indicado pela Tabela Brasileira de Composição de Alimentos, 85\% (NúCLEO DE ESTUDOS E PESQUISAS EM ALIMENTAÇÃO [NEPA], 2011).

A Figura 1 apresenta os gráficos do ganho de sólidos e perda de água durante a desidratação osmótica. 
Figura 1 - Ganho de sólidos e perda de água durante a desidratação osmótica de pedaços de peras, por até 4 horas
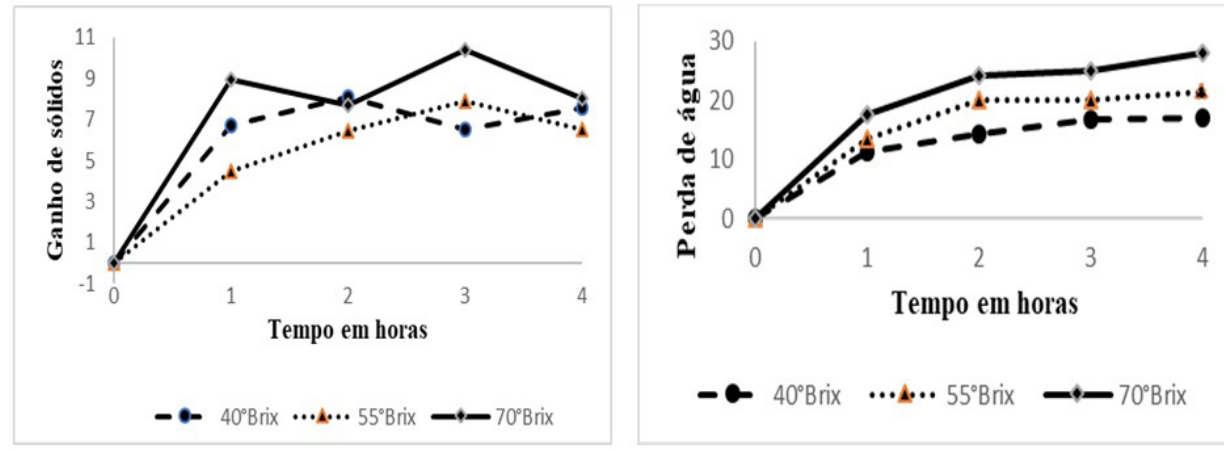

Fonte: Os autores.

A perda de água e o ganho de sólidos foram maiores na primeira hora da desidratação osmótica, tendendo ao equilíbrio, a partir da segunda hora. Esse comportamento foi observado por Souza Neto et al. (2005) durante a desidratação osmótica de manga nas concentrações de $45^{\circ}, 55^{\circ}$ e $65^{\circ}$ Brix. A perda de água foi maior durante a desidratação osmótica a $70^{\circ}$ Brix (28,09\%) e menor a $40^{\circ}$ Brix $(17,11 \%)$. Igualmente, o ganho de sólidos também foi maior a $70^{\circ}$ Brix (8,03\%). Enquanto a diferença de perda de água entre os tratamentos foi de até $10,98 \%$, a de ganho de sólidos foi de apenas 1,52\%. O aumento da perda de água no tratamento $70^{\circ}$ Brix pode ser explicado pela maior pressão osmótica no xarope, devido à maior concentração de sólidos (sacarose). Em frutos de murici submetidos à desidratação osmótica a $55^{\circ}$ Brix por 40 minutos, tendo como soluto a sacarose, a perda de água foi de 68\% (GUIMARÃES; SILVA 2008), sendo mais elevada que a observada nos pedaços de peras (Figura 1). A diminuição da quantidade de água e o incremento de sólidos podem contribuir para o aumento da vida de prateleira.

Os pedaços de peras, independentemente da concentração da solução osmótica, não apresentaram equivalência entre perda de água e de ganho de sólidos, como o verificado por Souza Neto et al. (2005) em mangas submetidas à desidratação osmótica nas concentrações de $45^{\circ}, 55^{\circ}$ e $65^{\circ}$ Brix.

Os valores médios obtidos para carboidratos, proteínas, lipídeos, fibras, umidade e cinzas estão apresentados na Tabela 1. 
Tabela 1 - Composição centesimal (\%) de peras desidratadas osmoticamente e, em seguida, secas convencionalmente

\begin{tabular}{ccccccc}
\hline Tratamento & Carboidratos & Proteínas & Lipídeos & Fibras & Umidade & Cinzas \\
\hline Controle & $50,86 \mathrm{~d}$ & $9,82 \mathrm{a}$ & $0,54 \mathrm{a}$ & $25,60 \mathrm{a}$ & $11,90 \mathrm{c}$ & $1,27 \mathrm{ab}$ \\
$40^{\circ}$ Brix & $56,62 \mathrm{c}$ & $5,33 \mathrm{~b}$ & $0,53 \mathrm{a}$ & $17,22 \mathrm{~b}$ & $18,88 \mathrm{~b}$ & $1,40 \mathrm{a}$ \\
$55^{\circ}$ Brix & $59,97 \mathrm{~b}$ & $4,20 \mathrm{c}$ & $0,54 \mathrm{a}$ & $15,44 \mathrm{~b}$ & $18,72 \mathrm{~b}$ & $1,11 \mathrm{~b}$ \\
$70^{\circ}$ Brix & $68,65 \mathrm{a}$ & $4,33 \mathrm{c}$ & $0,53 \mathrm{a}$ & $3,02 \mathrm{c}$ & $22,51 \mathrm{a}$ & $0,94 \mathrm{~b}$ \\
Teste F & $245,84^{*}$ & $843,12^{*}$ & $0,063 \mathrm{NS}$ & $167,60^{*}$ & $44,52^{*}$ & $16,59^{*}$ \\
\hline CV (\%) & 11,46 & 40,05 & 9,03 & 55,43 & 22,91 & 14,52 \\
\hline
\end{tabular}

Valores seguidos por letras iguais, na coluna, não diferem entre si pelo teste de Tukey, a $5 \%$ de probabilidade.

Fonte: Os autores

Os pedaços de peras submetidos à secagem convencional (controle) apresentaram teores de carboidratos inferiores aos submetidos à desidratação osmótica seguida por secagem convencional, os quais diferiram entre si também (Tabela 1). Quanto maior a concentração de açúcar da solução osmótica, maior o teor de carboidratos nos produtos desidratados.

Os pedaços do tratamento Controle apresentaram maiores valores de proteínas e fibras em relação aos desidratados osmoticamente, no entanto não diferiram dos demais tratamentos quanto ao teor de cinzas (Tabela 1). Quanto maior o teor de sólidos solúveis da solução osmótica, menor o conteúdo de proteínas e fibras. Não foram observadas diferenças quanto ao teor de lipídeos nos diferentes tratamentos, tendo em vista que o teor de lipídeo da pera in natura, segundo a Tabela Brasileira de Composição dos Alimentos (NEPA, 2011), é de aproximadamente 0,1 g 100 g-1 de amostra comestível, o que é muito baixo. Como os cubos foram desidratados, o teor de lipídeos encontrados foi proporcionalmente maior.

Os teores de umidade dos pedaços desidratados a $40^{\circ}$ Brix e $55^{\circ}$ Brix não diferiram estatisticamente, porém o valor encontrado nos pedaços do tratamento Controle foi inferior aos dos demais tratamentos, tendo em vista que não há barreira do açúcar para impedir a saída de água do tecido vegetal. Os pedaços submetidos à desidratação a $70^{\circ}$ Brix apresentaram maior umidade. 0 acompanhamento gravimétrico durante a secagem foi realizado parcialmente, devido à impossibilidade de monitoramento da secagem durante o período 
noturno, então os diferentes produtos foram mantidos pelo mesmo tempo no secador. Pode-se afirmar que a velocidade de remoção de água foi maior quanto menor a concentração de sólidos solúveis da solução osmótica.

Todos os tratamentos apresentaram teor de umidade dentro do estabelecido pela legislação para produtos desidratados, que é $25 \%$ p/p, e o tratamento que apresentou maior umidade foi o $70^{\circ}$ Brix, com 22,51\%. Esse tratamento provavelmente apresentou maior porcentagem por conta da camada de açúcar formada na superfície do pedaço, dificultando a saída de água durante a secagem.

A desidratação osmótica consiste na remoção de água da fruta por meio da imersão em uma solução hiperconcentrada de um soluto (PEREDA, 2005), levando a maior incremento de sólidos nos tecidos quanto maior a concentração da solução osmótica. Esse evento pode explicar o aumento de carboidratos e a redução de proteínas, cinzas e fibras em relação ao percentual do produto (Tabela 1), refletindo no valor energético total, que foi superior nos produtos desidratados em solução osmótica mais concentrada (Tabela 2), porém os pedaços desidratados a $40^{\circ}$ Brix não diferiram do Controle quanto ao valor energético (Tabela 2). Esses resultados são coerentes aos obtidos por Guimarães e Silva (2008), quando desidrataram murici osmoticamente a $55^{\circ}$ Brix e, em seguida, fizeram secagem convencional, para produção de murici-passa.

Os valores médios observados para valor energético total (VET), sólidos solúveis e pH estão apresentados na Tabela 2.

Tabela 2 - Valor energético total (VET), sólidos solúveis e $\mathrm{pH}$ de peras desidratadas osmoticamente e, em seguida, secas convencionalmente

\begin{tabular}{cccc}
\hline Tratamento & VET & Sólidos solúveis & PH \\
\hline Controle & $247,64 \mathrm{c}$ & $13,25 \mathrm{~d}$ & $4,37 \mathrm{a}$ \\
$40^{\circ}$ Brix & $252,63 \mathrm{C}$ & $41,58 \mathrm{C}$ & $4,35 \mathrm{a}$ \\
$55^{\circ}$ Brix & $261,63 \mathrm{~b}$ & $55,83 \mathrm{~b}$ & $4,40 \mathrm{a}$ \\
$70^{\circ}$ Brix & $296,69 \mathrm{a}$ & $71,08 \mathrm{a}$ & $4,29 \mathrm{a}$ \\
\hline Teste F & $159,74^{*}$ & $1788,72^{*}$ & $1,24 \mathrm{NS}$ \\
\hline CV (\%) & 7,62 & 49,02 & 1,71 \\
\hline
\end{tabular}

Valores seguidos por letras iguais, na coluna, não diferem entre si pelo teste de Tukey, a $5 \%$ de probabilidade.

Fonte: Os autores. 
Segundo Guimarães e Silva (2008), a técnica de desidratação osmótica aumenta o valor energético dos frutos. Os valores encontrados para sólidos solúveis foram diferentes em todos os tratamentos, tendo em vista que foram submetidos às diferentes soluções osmóticas. O teor de sólidos solúveis dos pedaços foi mais elevado com o aumento da concentração da solução osmótica (Tabela 2). O teor de sólidos solúveis é um importante parâmetro a ser observado, pois está relacionado ao sabor. O conteúdo superior a 9\% é desejável para comercialização (MENEZES; GOMES JUNIOR; SIMÕES, 2001). A desidratação osmótica aumenta o conteúdo de sólidos solúveis em frutos de murici, podendo favorecer sua comercialização (GUIMARÃES; SILVA, 2008).

De acordo com Park, Bin e Brod (2001), o pH das peras in natura varia de 2,6 a 5,4. No presente estudo, o pH das peras desidratadas variou entre 4,29 a 4,40. Os valores de $\mathrm{pH}$ não diferiram entre os tratamentos. Todos os produtos desidratados permaneceram com pH abaixo de 4,50, sendo classificados como muito ácidos, o que confere fator protetor ao produto contra desenvolvimento de microrganismos patogênicos (AZEREDO; BRITO, 2004).

$\mathrm{O} \mathrm{pH}$ do alimento, quando baixo, limita o desenvolvimento microbiano. Nos alimentos com $\mathrm{pH}>4,5$, predomina crescimento bacteriano, em condições favoráveis de atividade de água, e, nos com pH entre 4,0 e 4,5, predominam leveduras oxidativas ou fermentativas; mas, nos alimentos com $\mathrm{pH}<4,0$, desenvolvem-se, quase que exclusivamente, leveduras e bolores, quando o teor de água é favorável. No presente estudo, o desenvolvimento de microrganismos fica limitado devido ao reduzido teor de água e pH baixo. A adição de solutos e a secagem convencional reduziram o teor de água do alimento, prevenindo desenvolvimento por microrganismos.

Os valores médios encontrados para os compostos bioativos estão apresentados na Tabela 3. 
Tabela 3 - Fenóis totais, atividade antioxidante e taninos em peras desidratadas osmoticamente e, em seguida, secas convencionalmente

\begin{tabular}{cccc}
\hline Tratamento & Fenóis totais* $^{*}$ & Atividade antioxidante** & Taninos totais*** \\
\hline Controle & $108,41 \mathrm{~b}(98,44)$ & $47,43 \mathrm{a}(43,06)$ & $182,17 \mathrm{c}(165,42)$ \\
40 Brix & $118,87 \mathrm{a}(117,22)$ & $37,79 \mathrm{~b}(37,27)$ & $231,29 \mathrm{~b}(228,09)$ \\
55ㅇ Brix & $121,95 \mathrm{a}(120,02)$ & $44,85 \mathrm{a}(44,14)$ & $233,27 \mathrm{~b}(229,59)$ \\
70 Brix & $118,91 \mathrm{a}(131,22)$ & $37,82 \mathrm{a}(41,73)$ & $265,22 \mathrm{a}(292,69)$ \\
\hline Teste F & $31,59^{*}$ & $11,78^{*}$ & $29,66^{*}$ \\
\hline CV $(\%)$ & 4,76 & 11,75 & 14,17 \\
\hline
\end{tabular}

*Fenóis totais expressos em mg equivalente de ácido gálico 100 g-1 de amostra. **Expresso em IC 50 mg mL-1. ***Taninos totais expressos em mg equivalente de ácido tânico 100 g-1 de amostra. Os valores entre parênteses correspondem à conversão dos resultados para amostras com 20\% (bu) de umidade.

Fonte: Os autores.

Os tratamentos submetidos à desidratação osmótica não diferiram entre si quanto ao teor de fenóis totais, que foi inferior no Controle devido ao reduzido teor de água. Ao converter os resultados para amostras com 20\% (bu) de umidade, verifica-se na Tabela 3 que o teor de fenóis aumentou com o incremento de sólidos nos pedaços. Essa tendência de aumento também foi observada para a variável de taninos, cujos valores nas amostras com $20 \%$ (bu) de umidade aumentaram com a maior concentração da solução osmótica.

A atividade antioxidante foi avaliada usando o método de eliminação de radicais DPPH, no qual o composto antioxidante transfere elétrons para DPPH e perde a coloração roxa característica. A atividade antioxidante dos compostos, dada pela IC50, é calculada pela redução de 50\% da concentração inicial de DPPH; desta forma, quanto menor a IC50, maior a atividade antioxidante do composto analisado.

Observando os dados da Tabela 3, pode-se verificar que os pedaços submetidos à secagem convencional (controle) não diferiram dos desidratados osmoticamente a $55^{\circ}$ e $70^{\circ}$ Brix quanto à atividade antioxidante. Os desidratados a $40^{\circ}$ Brix apresentaram maior atividade antioxidante, considerando o valor obtido para a umidade real (Tabela 2). Ao converter os resultados para amostras com 20\% (bu), verifica-se a mesma tendência. Contudo os valores obtidos nas diferentes concentrações foram bem 
próximos, indicando pouca diferença na atividade antioxidante entres os tratamentos.

Landim (2016) observou que soluções osmóticas mais concentradas levaram à maior retenção da capacidade de sequestrar radicais livres. Afirmou que a incorporação de solutos nos tecidos da banana teve um efeito protetor, como barreira à lixiviação de sólidos solúveis, principalmente aqueles responsáveis pela capacidade antioxidante, como os taninos e os compostos fenólicos. Em contrapartida, Nowika, Wojdylo e Lech (2014) verificaram que a desidratação osmótica apresentou efeito negativo no teor de fenóis totais e na capacidade antioxidante de frutos de cereja ácida.

Segundo Jacob e Gopinadhan (2012), o agente osmótico aplicado na desidratação osmótica tem influência direta na retenção de compostos bioativos e na sua capacidade antioxidante. Além disso, diferentes frutas têm características distintas quanto à retenção de compostos fenólicos durante a desidratação. No entanto essa diferença pode ser correlacionada aos diversos perfis fenólicos encontrados em frutos, que apresentam comportamento diferente durante o processo.

A Figura 2 apresenta a frequência de consumo de frutos desidratados, independentemente da espécie, por julgadores não treinados.

Figura 2 - Frequência de consumo de frutos desidratados, independentemente da espécie, por julgadores não treinados, acadêmicos e servidores da UFMS

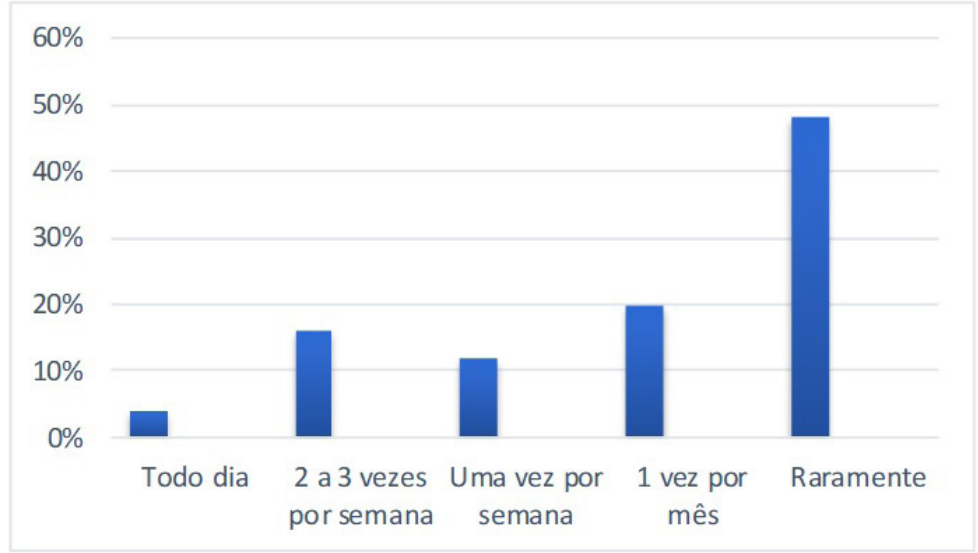

Fonte: Os autores. 
Ao serem questionados se gostam ou não de peras, $86 \%$ dos provadores afirmaram que gostam de peras, enquanto $14 \%$ afirmaram que não gostam do fruto. Cinquenta por cento dos provadores informaram que não consomem frutos desidratados e $50 \%$ informaram que consomem. Destes, $48 \%$ consomem raramente; $20 \%$, uma vez por mês; $12 \%$, uma vez por semana; $16 \%$, duas a três vezes por semana; e $3 \%$, todos os dias (Figura 2). Esses resultados sugerem que não é de costume a ingestão de frutos desidratados pela comunidade da UFMS, provavelmente pela falta de opções no mercado nacional.

Em todos os parâmetros avaliados, observou-se tendência de aumento das médias da aceitação das peras desidratadas osmoticamente em relação às desidratadas somente por secagem convencional (Tabela 4). O incremento de açúcar agradou os provadores, inclusive a consistência dos produtos, provavelmente resultante das mudanças ocorridas nas substâncias pécticas da parede celular, durante a desidratação osmótica, com solução a $60^{\circ} \mathrm{C}$, calor suficiente para alterar a textura do tecido. Os pedaços do tratamento Controle não foram imersos em solução aquecida, resultando em notas mais baixas para a consistência (Tabela 4).

As médias das notas das peras do tratamento $70^{\circ}$ Brix foram superiores a 5,2 e inferiores a 5,78, enquanto as do Controle foram superiores a 4,38 e inferiores a 4,62. A nota 5,0 indica "gostei ligeiramente" e a 6,0 "gostei moderadamente". As peras desidratadas em soluções osmóticas $40^{\circ}, 55^{\circ}$ e $70^{\circ}$ Brix não diferiram nos parâmetros de consistência, aroma, sabor e aspecto global. Em todos os parâmetros avaliados, observou-se tendência de aumento das médias, com a elevação de sólidos solúveis da solução osmótica (Tabela 4).

A "doçura" resultante do incremento de açúcar nos tecidos, que provavelmente apresentam a mesma quantidade de ácidos orgânicos, conferiu características agradáveis ao produto final. A aparência da pera desidratada osmoticamente a $70^{\circ}$ Brix foi provavelmente favorecida pelo "brilho" característico dos produtos açucarados, superior aos produtos completamente desidratados (BRANDÃO, et al., 2003), porém a aparência do Controle, $40^{\circ}$ Brix e $55^{\circ}$ Brix recebeu nota superior a 4,0 ("nem gostei, nem desgostei") e inferior a 5,0 ("gostei ligeiramente). 
Tabela 4 - Resultado (média, $n=50$ ) das notas atribuídas pelos julgadores para a aceitação sensorial das peras desidratadas em diferentes concentrações osmóticas e, em seguida, secas convencionalmente

\begin{tabular}{lccccc}
\hline Tratamento & Aparência & Consistência & Aroma & Sabor & Aspecto global \\
\hline Controle & $4,46 \mathrm{~b}$ & $4,52 \mathrm{~b}$ & $4,44 \mathrm{~b}$ & $4,38 \mathrm{~b}$ & $4,62 \mathrm{~b}$ \\
40 Brix & $4,46 \mathrm{~b}$ & $5,00 \mathrm{ab}$ & $4,84 \mathrm{ab}$ & $5,46 \mathrm{a}$ & $5,36 \mathrm{a}$ \\
55ㅇ Brix & $4,41 \mathrm{~b}$ & $5,22 \mathrm{ab}$ & $4,92 \mathrm{ab}$ & $5,71 \mathrm{a}$ & $5,47 \mathrm{a}$ \\
70 Brix & $5,20 \mathrm{a}$ & $5,41 \mathrm{a}$ & $5,33 \mathrm{a}$ & $5,92 \mathrm{a}$ & $5,78 \mathrm{a}$ \\
\hline Teste F & $2,8693^{*}$ & $3,1878^{*}$ & $3,1142^{*}$ & $9,9621^{*}$ & $6,8385^{*}$ \\
\hline CV (\%) & 34,37 & 30,54 & 30,26 & 29,09 & 25,04 \\
\hline
\end{tabular}

Valores seguidos por letras iguais, na coluna, não diferem entre si pelo teste de Tukey, a $5 \%$ de probabilidade.

Fonte: Os autores

Figura 3 - Aceitabilidade e intenção de compra de peras desidratadas em diferentes concentrações osmóticas e, em seguida, secas convencionalmente

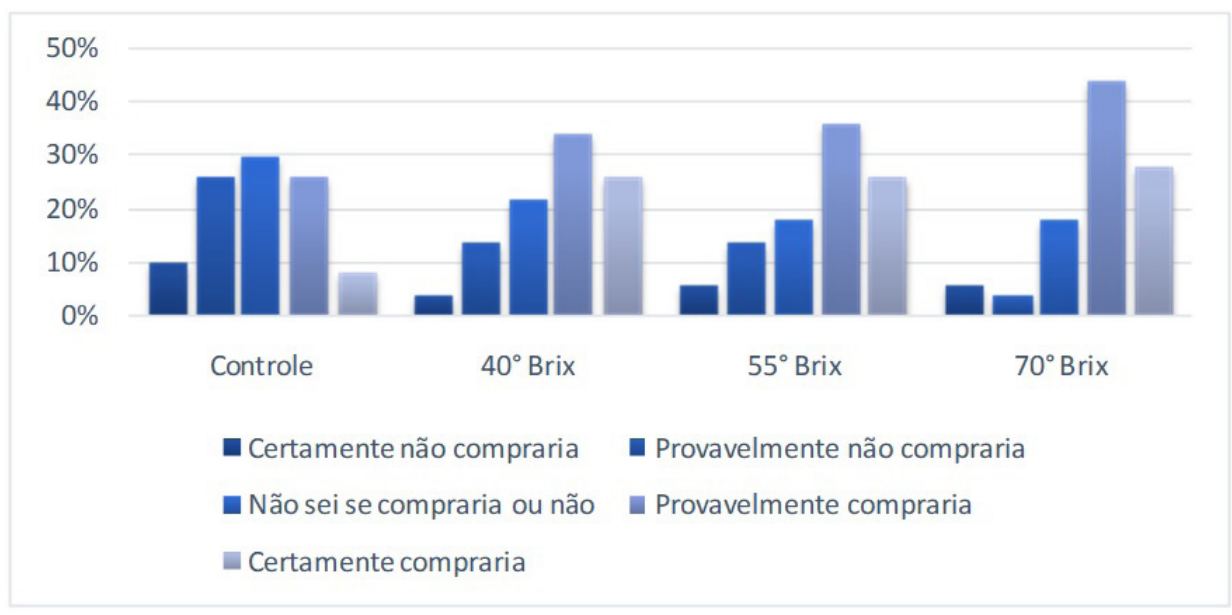

Fonte: Os autores

A Figura 3 apresenta a intenção de compra dos julgadores em relação às amostras de peras desidratadas, demonstrando uma maior frequência de respostas entre os conceitos "certamente compraria" e "provavelmente compraria". Os resultados indicam que a atitude de compra foi positiva para 
as peras em geral, com destaque para as desidratadas a $70^{\circ}$ Brix, com $44 \%$ dos provadores que responderam "provavelmente compraria", enquanto as desidratadas a $40^{\circ}$ Brix e $55^{\circ}$ Brix tiveram porcentagens de $34 \%$ e $36 \%$, respectivamente. $\mathrm{O}$ tratamento que não sofreu a imersão no xarope obteve a maior frequência de respostas nos conceitos "não sei se compraria ou não" (26\%) e "certamente não compraria" (10\%), indicando uma intenção de compra negativa. A porcentagem de provadores que responderam que provavelmente não comprariam os pedaços desidratados a $70^{\circ}$ Brix foi inferior a $5 \%$ - esta porcentagem aumentou nas amostras desidratadas em solução com menor concentração de açúcar.

\section{CONCLUSÕES}

O incremento de sólidos solúveis na solução osmótica proporciona aumento dos teores de carboidratos, do valor energético, dos fenóis totais e dos taninos das peras desidratadas osmoticamente, assim como maior aceitabilidade sensorial em relação às peras desidratadas somente por secagem.

A capacidade em sequestrar radicais livres foi mais elevada nos produtos desidratados osmoticamente em $40^{\circ}$ Brix.

\section{REFERÊNCIAS}

AZEREDO, Henriette Monteiro Cordeiro; BRITO, Edy S. Tendências em Conservação de Alimentos. In: AZEREDO, H. M. C. Fundamentos de Estabilidade de Alimentos. Fortaleza: Embrapa Agroindústria Tropical, 2004. p. 135-50.

BRANDÃO, Maria Cristina Cabral; MAIA, Geraldo Arraes; LIMA, Dorasilvia Pontes; PARENTE, Expedito José de Sá; CAMPELLO, Claudio Cabral; NASSU, Renata Tieko; FEITOSA, Terezinha; SOUSA, Paulo Henrique Machado. Análise físico-química, microbiológica e sensorial de frutos de manga submetidos à desidratação osmóticosolar. Revista Brasileira de Fruticultura, Jaboticabal, v. 25, n. 1, p. 38-41, 2003.

DIONELLO, Rafael G.; BERBERT, Pedro A.; MOLINA, Marília A. B.; PEREIRA, Rozimar C.; VIANA, Alexandre P.; CARLESSO, Vinicius O. Desidratação osmótica de frutos de duas cultivares de abacaxi em xarope de açúcar invertido. Revista Brasileira de Engenharia Agrícola e Ambiental, Campina Grande, v. 13, n. 5, p.596-605, 2009. 
GUIMARÃES, Marília Mendonça; SILVA, Maria Sebastiana. Valor nutricional e características químicas e físicas de frutos de murici-passa (Byrsonima verbascifolia). Ciência e Tecnologia de Alimentos, Campinas, v. 28, n. 4, p. 817-21, 2008.

INSTITUTO ADOLFO LUTZ. Métodos físico-químicos para análises de alimentos. São Paulo: Instituto Adolfo Lutz, 2008. 1020 p.

JACOB, Jissy K.; GOPINADHAN Paliyathb. Infusion of fruits with nutraceuticals and health regulatory components for enhanced functionality. Food Research International, v. 45, p. 93-102, 2012.

LANDIM, Ana Paula Miguel. Desidratação osmótica de banana utilizando soluções de fruto-oligossacarídeos e xarope de milho em diferentes temperaturas. 2016. 97 p. Orientadora: Maria Ivone Martins Jacintho Barbosa. Dissertação (Mestrado em Ciência e Tecnologia de Alimentos) - Universidade Federal Rural do Rio de Janeiro, Seropédica, RJ, 2016.

LOMBARDI, Sergio Ricardo Bolte; MORAES, Dario Mult; CAMELATTO, Darcy. Avaliação do crescimento e da maturação pós-colheita de peras da cultivar Shinsseiki. Pesquisa Agropecuária Brasileira, Brasília, v. 35, n. 12, p. 2399-405, 2000.

MENEZES, Josivan B.; GOMES JUNIOR, Julio; SIMÕES, Adriano do N. Armazenamento de dois genótipos de melão amarelo sob condições ambiente. Horticultura Brasileira, Vitória da Conquista, v. 19, n. 1, p. 42-9, 2001.

NOWICKA, Paulina; WOJDYLO Aneta; LECH, Krzysztof; Figiel, Adam. Influence of osmodehydration combined drying method on the bioactive potential of sour cherry fruits. Food and Bioprocess Technology, v. 8, p. 824-36, 2014.

NÚCLEO DE ESTUDOS E PESQUISAS EM ALIMENTAÇÃO. Tabela Brasileira de Composição de Alimentos - Taco. 4. ed. rev. e ampl. Campinas: Nepa/Unicamp, 2011.

PARK, Kil Jin; BIN, Adriana; BROD, Fernando Pedro Reis. Obtenção das isotermas de sorção e modelagem matemática para a pêra bartlett (pyrus sp.) com e sem desidratação osmótica. Ciência e Tecnologia de Alimentos, Campinas, v. 21, n. 1, p. 288-92, 2001.

PEREDA, Juan A. Ordoñez. Tecnologia de alimentos. Porto Alegre: Artmed, 2005.

ROESLER, Roberta et al. Atividade antioxidante de frutas do cerrado. Ciência e Tecnologia de Alimentos, Campinas, v. 27, n. 1, p. 53-60, 2007. 
SOUZA NETO, Manoel Alves; MAIA, Geraldo Arraes; LIMA, Janice Ribeiro; FIGUEIREDO, Raimundo Wilane; SOUZA FILHO, Men de Sá Moreira; LIMA, Andréa da Silva. Desidratação osmótica de manga seguida de secagem convencional: avaliação das variáveis de processo. Ciência e Agrotecnologia, Lavras, v. 29, n. 5, p. 1021-28, 2005.

SWAIN, T.; HILLS, W. E. The phenolics constituents of Prumus domestica. I. - the quantitative analysis of phenolic constituents. Journal of the Science of Food and Agriculture, London, v. 10, n. 1, p. 63-8, 1959.

TAKAHASHI, Marina Sakae; RAVELLI, Adermival Sargi. Cinética da concentração osmótica de pera. Ciências Exatas e Tecnológicas, v. 4, p. 23-31, 2005. 